\title{
NARRATOLOGY AND TAXONOMY: A RESPONSE TO BRIAN RICHARDSON
}

Maria Mäkelä, University of Tampere, Finland

Style 50:4 (2016), 462-467

Unnatural foregroundings of textuality and artistic motivation have never been automatized and never will be. Unnaturalness, for me, is the cognitive flip side of the "natural" reading process, the counterforce that makes us appreciate and restore the distorted and mediated nature of fictional and textual representation. This stance associates my work-more or less loosely_with the unnaturalists. As a young doctoral student, I was impressed and inspired by Richardson's radically antimimetic take in Unnatural Voices, and I continue to admire the fervor with which he is establishing this new paradigm, continually drawing in new texts and new people. Yet I have major reservations concerning some of the very fundamentals of Richardson's approach, as well as with the narrative-theoretical methodology that follows from such a groundwork. Here I take up three such reservations that, in the end, all boil down to this question: what role does taxonomy play in contemporary narrative theory (and should it even play any role)?

\section{UNNATURAL NARRATIVES OR UNNATURAL NARRATOLOGY?}

When we first engaged in the business of the unnatural during the 2007 Narrative Conference in Washington, what we had in mind was a critical, even provocative movement that would contest the homogenizing side effects of contemporary narratology — the very same "mimetic bias" to which Richardson rightly draws our attention in his Target Essay. But what I particularly had in mind was a critique of the notions of reading and interpretation promoted by cognitive narratology: the perception of literature primarily through conversational story schemata; the analogies between real-life experiences and literary mediation that seemed too easy; and the tendency to construct the reader as a sense-maker who always opts for the primary, the plausible, the coherent, and the unambiguous. So for me, unnatural narratology was never about strange narratives but about the distortion of human experience that even the most realist literary narrative can create by its overly verbalized, overly structured, and overly intentional design. By "overly" I mean in relation to both conversational storytelling and our cognitive take on the real world. Furthermore, I thought that, when understood in this manner, unnaturalness would be the 
perfect new touchstone for the dominant cognitive paradigm. I thought that the term "unnatural" was a provocation, not a category for certain genres, texts, or narrative devices.

And, behold, in recent years the narratological community has witnessed the ferreting out of ever more bizarre, nonconventional, noncommunicative, or self-eradicating texts. The theoretical provocation has turned into a taxonomic project that resembles an entomological expedition in the Amazon (see Tammi). Who will find the most exotic, unprecedented species? For this, I must blame Richardson and his passion for extensive, overwhelming lists of "unnatural narratives" and their categorization; he is the indisputable winner of this entomological contest. To be sure, new test cases for narratological analyses are welcome-I'm glad that someone moves the Austens, Jameses, and Hemingways aside for a while. Yet if we genuinely wish to contest the cognitive paradigm, we should not focus on classifying literary texts as more or less unnatural, but instead try to revolutionize our all-too-naturalized assumptions about the frames and dynamics of reading. In other words, we should do unnatural narratology instead of hunting for unnatural narratives. If we confront natural narratology merely with a new corpus, we fail to address the very fundamentals of the cognitive approachthe universalist claims about meaning-making and the overarching principle of economy, for example.

In Monika Fludernik's groundbreaking natural narratology (the original inspiration for the unnaturalist movement), there is no place for such a thing as a "natural novel." As I have repeatedly argued elsewhere, placing the realist novel at the same end of the natural-unnatural axis with the naturally occurring conversational narrative misses Fludernik's original point, which relates to the anchoring of readerly frames in the real-life experiential schemata shared by the teller and the reader. Natural—and more generally, cognitive-narratology does not classify texts but instead hypothesizes on the reader's dynamic narrative engagement with all kinds of texts, thus returning narratology to its structuralist roots-back to the search for the "deep structure" of narrative. Consequently, as a theoretical praxis, natural narratology is much more flexible than unnatural narratology in its classificatory variant; it is ultimately able to encompass most of the "unnatural narratives" ferreted out by the unnaturalists and incorporate the ostensible challenges they issue into its own explanatory framework (Alber, "Impossible"; Fludernik, "How Natural"). By contrast, unnatural narratology risks appearing as an "app" to the grand theory, scanning the history of occidental literature merely on the lookout for exceptions to the rules. 


\section{UNNATURAL GENRE/TEXT/ELEMENT?}

Richardson's essay summarizes extensively the sometimes starkly contrasting views of his colleagues on what can be labeled an "unnatural narrative," but it does not reflect on the fact that his call for a narrative-theoretical revision of the corpus has indeed resulted in such a disturbing mishmash of definitions and taxonomies. Richardson himself places a heavy emphasis on postmodernist texts and their well-known predecessors in his theory, thus sometimes implying that unnaturalness could be deemed a generic feature. However, genericity suggests conventionality, a qualifier Richardson reserves for "mimetic," realist texts, and "nonmimetic," conventionally supernatural narratives such as fairy tales. Yet the typical unnaturalities discussed by Richardson—such as mutually inconsistent story lines or self-eradicating narration—are, by now, established conventions of the nouveau roman and postmodernism, and, as such, are just as vulnerable to Shklovskian automatization as any realist or modernist technique (omniscient narration, stream of consciousness). Thus, I find conventionality a weak criterion for separating antimimetic texts from the nonmimetic. There seems to be an inherent tension in the way Richardson both celebrates the transgressiveness of unnatural narratives and at the same time typologizes and thus conventionalizes their representational techniques.

The essay is permeated by collegiality, and it conveys the good spirit with which Richardson has developed the unnatural paradigm in dialogue with not always completely likeminded scholars. The theoretical congeniality shows in the way Richardson moves somewhat too easily from a strict definition of unnatural narrative to agreeing that there can be unnatural "elements" in narratives that are otherwise strongly framed as realist. One is left wondering: if unnaturalness is a text-immanent feature, how much unnaturalness is enough to make the entire narrative unnatural? Is it enough that the text triggers an unnaturalist (postmodernist) convention, such as metafictionality? How should we conceive of the structural and interpretive relationship between unnatural "elements" and the mimetic macro-frame that nevertheless is able to "subsume" (as Richardson writes) those rebellious elements (or, vice versa, realist elements subsumed within an unnatural macro-frame; see Fludernik, "How Natural" 363)?

While I consider Richardson's critique of cognitive narratology courageous and sometimes well-placed, the unnaturalists could in fact take a hint from the cognitivists' attention to reading as a dynamic process, which has much more to do with primacy and recency effects 
(as already suggested by narratologists of the Tel Aviv School in 1970s) than with rigorous categorization. For cognitive narratology and its formalist predecessors, the reading process is governed more by prototypifying frames than by any encyclopedic urge. Then again, unnatural narratology has not addressed the problem of interpretation properly, partly because the cognitive turn has shifted the focus from interpretation to mapping, navigation, and sensemaking, and in this respect, the unnatural narratologists have, indeed, followed the dominant cognitive paradigm. One way to bridge the gap between our understanding of the processes of cognitive apperception and literary interpretation would, perhaps, be to study how the natural and the unnatural work together in the reading process. From a cognitivist perspective, the reading process is grounded on frame selection and frame blending, but I would suggest that literary interpretation is precisely dependent on the possibility of playing with the frames like a juggler, trying to keep as many balls as possible in the air simultaneously. This "unnatural" interpretive act would explain why, for example, immersivity and metafictionality as effects of reading can prevail at the same time. In fact, Richardson also considers this kind of interpretive double exposure to be a distinctive feature of unnatural narratives. Yet what I'm suggesting, in essence, is that the unnatural is not a type or even a quality of a specific narrative, nor even of a specific narrative technique or "element," but a frame of reading.

\section{THE RANGE AND THE COMPLETENESS OF NARRATIVE THEORY}

The ethos of Richardson's essay resonates strongly with the project of postclassical narratology, outlined by David Herman already in 1999 as the reworking of narrative-theoretical methods against texts "that classical narratology either failed or chose not to explore" ("Introduction: Narratologies" 2). Indeed, Richardson's ultimate discontent with contemporary narrative theory seems to be its incompleteness, to which he refers several times. I wonder what a complete narrative theory would look like. While Richardson and many other unnaturalists (myself included) pointedly reject the universalist stance promoted by cognitivist approaches, the alternative route to comprehensiveness, represented by the Target Essay, is a reactive attitude to new forms and types of unnaturalness that results in new descriptive categories. Can this type of reactive attitude actually form the core of postclassical narratology—does it issue a genuine theoretical challenge to cognitive approaches? 
I'm reminded of the famous empty slot in Genette's cross-tabulation of voice and mood, the one reserved for the allegedly unpreceded type which nevertheless exists in theory: homodiegetic narration with external focalization (Narrative Discourse Revisited 121). However, as Genette tells us, it was only after outlining his typology of narrative situations that he went to the library and found more or less worthy candidates (e.g., Camus's L'Etranger and many thrillers) to fill in the slot. He quotes Borges: "It is enough that a book be possible for it to exist" ("The Library of Babel," qtd. in Narrative Discourse Revisited 121). The following several-page-long (121-27) discussion on the empty slot for this seemingly "impossible" narrative situation is something that every unnaturalist should read. The ultimate strength of Genette's theory building is its proactivity: the theory itself is able to autogenically produce the forms it aims to describe. Despite their seeming structuralist rigidity, Genette's theories are endlessly productive and, as such, form a well-matched dialogical counterpart to the boundlessly emerging new narratives. And, as we all know, in spite of (or maybe precisely because of) being repeatedly contested in contemporary narratology, Genette's theories are still an elementary part of the hard core of narrative theory, inspiring new apps, such as Richardson's astute considerations on second-person and we-narratives.

To my mind, we cannot ground a theory on exceptions to the rule. For example, if we wish to challenge the dominantly "natural" narrative prototype, we should not only look for deviations but also work within the alleged prototype, which includes established literary conventions and narratives that some of us call "ordinary realist texts." Then again, if one necessarily wants to continue the entomological expedition in the Amazon, one can be certain to never go out of business - the reserves of the rainforest are endless, and rare and exotic narrative strategies cannot become extinct.

\section{WORKS CITED}

Alber, Jan. "Impossible Storyworlds - and What to Do with Them." StoryWorlds: A Journal of Narrative Studies 1 (2009), 79-96. Print.

Fludernik, Monika. “How Natural Is 'Unnatural Narratology’; or, What Is Unnatural about Unnatural Narratology?” Narrative 20:3 (2012), 357-370. Print.

Genette, Gérard. Narrative Discourse Revisited. Transl. by Jane E. Lewin. Ithaca, NY: Cornell UP, 1988. Print. [Nouveau discours du récit 1983.] 
Herman, David. "Introduction: Narratologies." Narratologies: New Perspectives on Narrative Analysis. Columbus: Ohio State UP, 1999. 1-30. Print.

Tammi, Pekka. "Exploring terra incognita." FREE language INDIRECT translation DISCOURSE narratology: Linguistic, Translatological and Literary-Theoretical Encounters of FID. Eds. Pekka Tammi and Hannu Tommola. Tampere: Tampere UP, 2006. 159-73. Print. 